\title{
Understanding the hydrodynamics of a size sorting grid in a crustacean fishery
}

\author{
Veiga-Malta, T.; Breddermann, K.; Feekings, Jordan P.; Krag, Ludvig Ahm; Paschen, M.
}

Published in:

Ocean Engineering

Link to article, DOI:

10.1016/j.oceaneng.2020.106961

Publication date:

2020

Document Version

Peer reviewed version

Link back to DTU Orbit

Citation $(A P A)$ :

Veiga-Malta, T., Breddermann, K., Feekings, J. P., Krag, L. A., \& Paschen, M. (2020). Understanding the hydrodynamics of a size sorting grid in a crustacean fishery. Ocean Engineering, 198, [106961].

https://doi.org/10.1016/j.oceaneng.2020.106961

\section{General rights}

Copyright and moral rights for the publications made accessible in the public portal are retained by the authors and/or other copyright owners and it is a condition of accessing publications that users recognise and abide by the legal requirements associated with these rights.

- Users may download and print one copy of any publication from the public portal for the purpose of private study or research.

- You may not further distribute the material or use it for any profit-making activity or commercial gain

- You may freely distribute the URL identifying the publication in the public portal 
Engineering

Manuscript Number: OE-D-19-00852R1

Title: Understanding the hydrodynamics of a size sorting grid in a crustacean fishery

Article Type: Full length article

Keywords: Grid angle; bar shape; hydrodynamics; wind tunnel; grid porosity; Crangon crangon

Corresponding Author: Mr. Tiago Veiga-Malta,

Corresponding Author's Institution:

First Author: Tiago Veiga-Malta

Order of Authors: Tiago Veiga-Malta; Karsten Breddermann; Jordan P Feekings; Ludvig A Krag; Mathias Paschen

Abstract: A size-sorting grid with a $6 \mathrm{~mm}$ bar spacing was proposed for a brown shrimp (Crangon crangon) beam trawl fishery. Considering the bar spacing, concerns regarding the hydrodynamics of such grid were raised. Here we experimentally investigated the hydrodynamics of four grid designs in a wind tunnel to identify which parameters mostly affected flow. By observing the Reynolds similarity criteria, we ensured that the measurement results in the wind tunnel are applicable in water. The four grids were tested at different angles of attack and wind velocities. Porosity and the inclination of the grid were found to be the main factors affecting the flow. The shape of the bars was also found to affect the flow, although to a lesser extent than porosity and angle, indicating that grid effectiveness is a function of how they are designed and installed in the fishing gear. 


\section{Highlights}

2 - The flow through and along a sorting grid was successfully investigated in a wind tunnel

3 - Grid's porosity was found to be the main factor affecting the flow through the grid

4 - Empirical formulae are given to calculate the flow through and along the grid

5 - Poor grid design and mounting in a trawl can lead to low hydrodynamics performance 


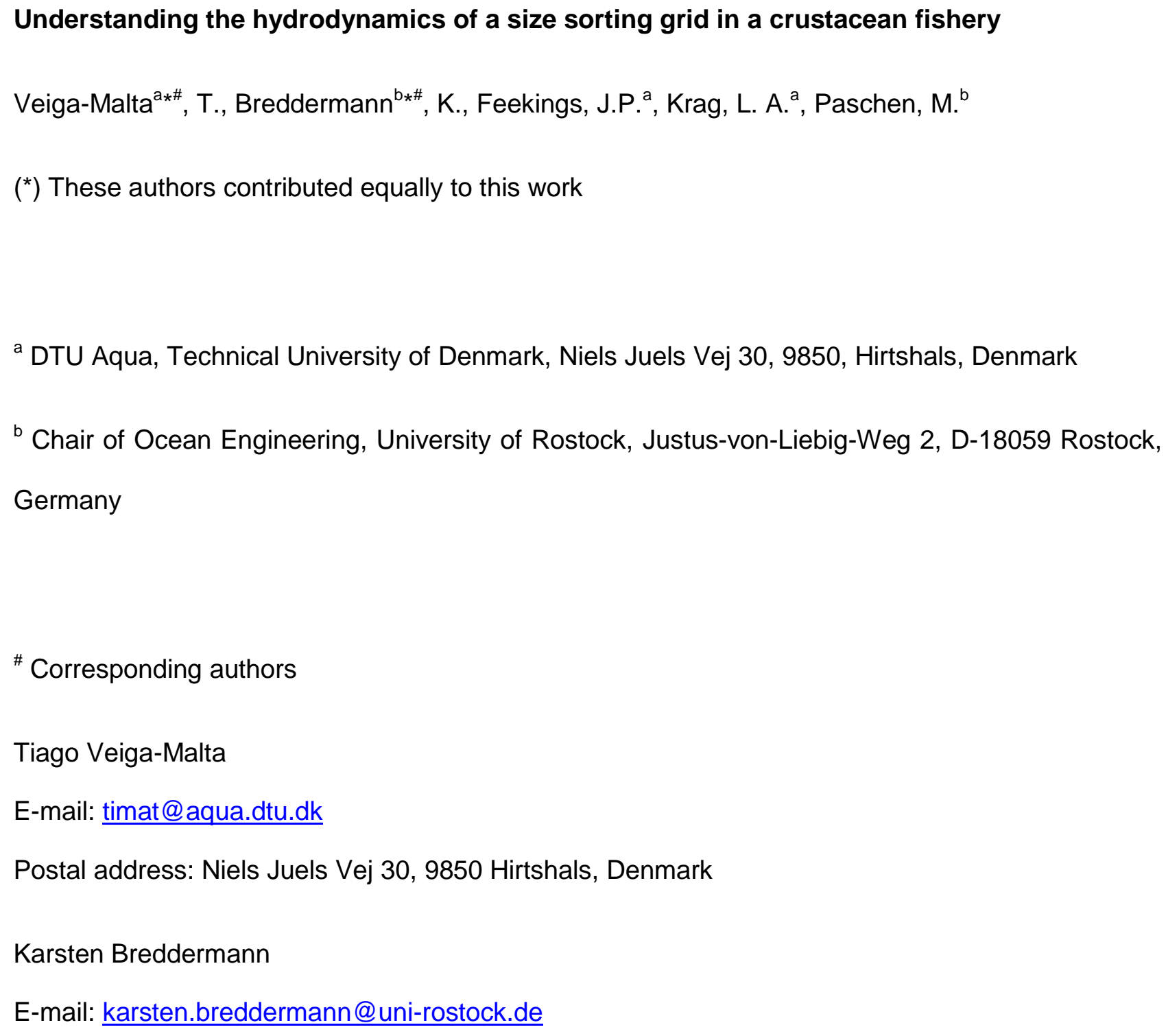




\begin{abstract}
A size-sorting grid with a $6 \mathrm{~mm}$ bar spacing was proposed for a brown shrimp (Crangon crangon) beam trawl fishery. Considering the bar spacing, concerns regarding the hydrodynamics of such grid were raised. Here we experimentally investigated the hydrodynamics of four grid designs in a wind tunnel to identify which parameters mostly affected flow. By observing the Reynolds similarity criteria, we ensured that the measurement results in the wind tunnel are applicable in water. The four grids were tested at different angles of attack and wind velocities. Porosity and the inclination of the grid were found to be the main factors affecting the flow. The shape of the bars was also found to affect the flow, although to a lesser extent than porosity and angle, indicating that grid effectiveness is a function of how they are designed and installed in the fishing gear.
\end{abstract}

\title{
Keywords
}

Grid angle, bar shape, hydrodynamics, wind tunnel, grid porosity, Crangon crangon 


\section{Introduction}

In crustacean trawl fisheries, grids are one of the most common and successful selective devices used globally to reduce unwanted catch (Eayrs, 2007; Catchpole and Revill, 2008; Lövgren et al., 2016). Traditionally, grids consist of a physical barrier of vertical or horizontal bars, of a given bar shape and spacing used to release or filter catch into an alternative codend (e.g. Isaksen et al., 1992; Eayrs, 2007). Grids have typically been used for two different goals in fisheries. First, they can be used as a by-catch reduction device, with bar spacing set to allow individuals within the size range of target species to enter the codend, while larger non-target species, unable of passing through the grid, are ejected through an opening (Grimaldo and Larsen, 2005; Kvalsvik et al., 2006; Eayrs, 2007). Additionally, grids can be used as size sorting devices, where small individuals may escape before they reach the codend (Kvalsvik et al., 2002; Larsen et al., 2016; 2018). Usually, this latter size sorting requires the use of a smaller space between the grid's bars, particularly if the target species is small, such as shrimps.

The brown shrimp (Crangon crangon Linnaeus, 1758) beam trawl fishery is an important fishery in the North Sea with an international fleet of approximately 550 vessels, mainly from the Netherlands, Germany and Denmark. In the recent years, it generated annual landings of approximately 30000 tonnes (ICES, 2016). This fishery is certified by the Marine Stewardship Council (MSC) since 2017. As part of the MSC requirements to maintain the certification, the fishery has to increase the minimum mesh size (diamond mesh) from $22 \mathrm{~mm}$ in 2017 to $26 \mathrm{~mm}$ in 2021 (MSC, 2017). Concerned that the increase in mesh size would result in a substantial loss of marketable size brown shrimp, the Danish fishermen proposed the introduction of a size sorting grid with a bar spacing of $6 \mathrm{~mm}$ as a possible alternative to the MSC requirements.

Adoption of the proposed grid raised concerns about capture efficiency due to water flow through the grid, as previously reported for grids with even larger bar spacing (Grimaldo and Larsen, 2005; Grimaldo, 2006). The sorting effectiveness of fishing grids has been shown to be influenced by the 
shape and spacing between grid bars (Riedel and DeAlteris, 1995). If the porosity (open area/total area) of the grid is too low, i.e. the flow through the grid will be too low, the capture efficiency of the grid can be negatively impacted (Grimaldo and Larsen, 2005; Grimaldo, 2006; Grimaldo et al., 2015; Sistiaga et al., 2016). In the case of brown shrimp, a species with relatively little swimming capacity (Arnott et al., 1998), the water flow that goes through the grid and that is deflected by it is of even greater importance (Valdemarsen, 1989). A too high water flow through the grid may result in a loss of commercial sized individuals due to them being pushed through the bars, while if the velocity is too low, a relatively large portion of catch may not contact the grid, thus decreasing the effectiveness of the grid (He and Balzano, 2012). Therefore, investigating the hydrodynamics of a grid, and in particular the flow through it, is necessary when designing a sorting grid, especially in fisheries with small target species, as in the brown shrimp fishery.

In addition to the grid porosity, other factors influence grid hydrodynamics. The grid angle of attack has been shown to affect the water flow through the grid (Riedel and DeAlteris, 1995; Maurstad, 1997), although showing contradictory results. Riedel and DeAlteris (1995) suggest that at lower angles less flow is lost when passing through the grid bars, while Maurstad (1997) suggest the opposite. The shape of the bars is also known to influence the hydrodynamics of a grid, although it has been suggested that the influence of this factor is of less importance than the previous factors (Riedel and DeAlteris, 1995; Grimaldo, 2006). Grid hydrodynamics has been identified as an important factor for their success in fisheries (e.g. Kvalsvik et al., 2002; Grimaldo and Larsen, 2005; Kvalsvik et al., 2006; He and Balzano, 2012; Larsen et al., 2016, 2018). Only one study has effectively identified what parameters affect the hydrodynamics of grids. In Riedel and DeAlteris (1995), a species selective grid with a bar spacing of $19 \mathrm{~mm}$ was tested, a bar spacing 3 times larger than the size selective grid proposed for the brown shrimp fishery $(6 \mathrm{~mm})$. Thus, there is the need to better understand the hydrodynamics around size selective grids that typically have smaller bar spacing. 
Wind tunnels have been previously used to successfully describe the hydrodynamics of other towed fishing gears (Reite and Sørensen, 2006; Paschen et al., 2008; Mellibovsky et al., 2015, 2018). Within a Reynolds number based test regime, it is often advantageous to conduct experiments in a wind tunnel rather than in a flume tank. That is primarily because none of the equipment needs to be waterproof. Furthermore, there is better access to the experiment and changes are more easily executed. Several grids have been developed and tested by both industry and scientists, with measurements of hydrodynamics often lacking. Therefore, this approach could be characterized as a trial and error approach (Graham, 2010). This type of approach can be quite costly, both in terms of time and money. Hence, the aim of this study was to understand the effect of different parameters on the hydrodynamics of grids through the use of a systematic experimental design in a wind tunnel. The parameters tested were grid porosity, angle of attack, shape of grid's bars, and approaching flow velocity.

\section{Material and Methods}

Four glass fibre reinforces plastic grids with different bar cross section were tested (Fig. 1). Throughout this study, the different grids tested were named according to the cross sectional shape of their bars. The grid with a cylindrical cross section was referred to as "Cylindrical", the grid with rectangular bars with rounded corners was referred to as "Rectangular", and the two grids with drop shaped bars were referred to as "Drop 4" and "Drop 8", based on the width of the bars. The drop shaped bars consist of a circular front part with a rear triangular shape. The rectangular, cylindrical and Drop 8 bars are used commercial in different fisheries in Denmark, while Drop 4 was designed for this experiment as a potential solution for a grid with $6 \mathrm{~mm}$ bar spacing.

The porosity $\beta$ of the grids, the ratio of the open area to the total area, was calculated according to

$$
\beta=\frac{b s}{w+b s}
$$


where $w$ denotes the width of the bar and $b s$ the bar spacing. With a bar spacing of $6 \mathrm{~mm}$ the porosities were 0.43 for the cylindrical and drop $8,0.60$ for the drop 4 , and 0.61 for the rectangular.

Experiments were conducted at the University of Rostock Ocean Engineering Department subsonic wind tunnel, a return-circuit Göttingen type tunnel with a $2.8 \mathrm{~m}$ long open test section. The side length of the square nozzle outlet was $1.4 \mathrm{~m}$. The wind velocity was determined by a differential static pressure measurement at the inlet and outlet of the nozzle. The pressure was measured with a differential pressure transducer (Baratron 220DD from MKS Instruments, Inc.) with a measurement range of 20 Torr, i.e. 2,666 $\mathrm{Pa}$. To determine the air density, the ambient barometric pressure (transducer model 3.1157.10.161 from Adolf Thies GmbH \& Co. KG), the temperature and humidity (model 6605 probe and transducer unit model 6651 from testo AG) were measured. With the measurement technique used, the wind velocity can be determined with a relative uncertainty of $2 \%$.

By choosing proper conditions in the wind tunnel the flow patterns and loads on the grids are comparable to conditions in water. These conditions are achieved if geometric, kinematic and dynamic similarities are met. Geometric similarity exists when the wind tunnel model and full-scale objects are similar in shape. Since the grids were tested in full-scale, geometric similarity was achieved. Kinematic similarity is met when the ratios of corresponding time intervals are constant in time dependent motions, i.e., the streamlines are similar. Kinematic similarity exists when flow velocities are comparable, taking into account the fluid properties. Dynamic similarity exists when the ratios of forces acting on the model and the grid are the same. For the grids, assuming a steady flow, the ratio of the convective inertia forces and the viscous forces are constitutive for the flow patterns. Thus, dynamic similarity is achieved by keeping constant the ratio of the convective inertia forces to the viscous forces, expressed by the Reynolds number:

$$
R e=\frac{u \cdot L}{v}=\text { const. } \Rightarrow R e_{\text {model }}=R e_{\text {full-scale }}
$$


where $L$ is the characteristic length (here: width of the gird bar), $u$ the characteristic velocity and $v$ the kinematic viscosity of the fluid. For the wind tunnel velocity, or approach velocity, $u_{0}$ it follows:

$$
u_{0}=u_{\text {water }} \cdot \frac{v_{\text {air }}}{v_{\text {water }}}
$$

In the brown shrimp beam trawl fishery, trawls are typically towed at 3 to $3.5 \mathrm{kn}$. To allow for variation in the towing velocity, 2, 3 and $4 \mathrm{kn}$ velocities were investigated. With $v_{\text {air }}=14.6 \cdot 10^{-6}$ $\mathrm{m}^{2} / \mathrm{s}$ and $v_{\text {water }}=1.36 \cdot 10^{-6} \mathrm{~m}^{2} / \mathrm{s}$ the approach velocities in the wind tunnel were calculated as approximately 11.5, 17.3 and $23.1 \mathrm{~m} / \mathrm{s}$ (e.g. Fridman, 1986; Ward and Ferro, 1993).

\subsection{Experimental Design}

Grids were attached to a steel frame fixed to a turntable to allow for full $360^{\circ}$ rotation (Fig. 2). A 3-D coordinate system was used to decompose wind flow measurements into three axes (Figure 3). The $x$-axis of the global right-handed coordinate system aligned with the direction of the undisturbed flow in the wind tunnel. The $z$-axis pointed downward from the test section. The $y$-axis pointed towards the reader. The $x$ - and $z$-axes lay in the symmetry plane of the grid. Measurements in front and behind the grid were obtained in consecutive and not simultaneous runs to avoid unexpected effects to the flow from the presence of the probe in the test area. For measurements in front of the grid, the origins of the coordinate systems lay in the plane spanned by the leading edges of the grid bars, while for measurements behind the grid, the origins lay in the plane spanned by the trailing edge of the grid bars. The local grid fixed coordinate system comprised of a normal axis, $n$, to the grid plane, a tangential axis, $t$, along the grid bar and a tangential axis aligned with the $y$-axis but of opposite direction. The grid angle of attack was the angle between the $x$-axis and $t$, denoted by $\alpha$ in Fig. 3. Grid angles of $90^{\circ}, 60^{\circ}, 45^{\circ}$ and $30^{\circ}$ were investigated. The $90^{\circ}$ angle of attack was considered in the experimental design, as a reference point, since at this angle the resistance of the grid to the flow is at its maximum. The remaining angles of attack investigated represent the typical range of angles used in fisheries for grids. Complete set of measurements were obtained per treatment combination, i.e. a complete set of 
measurement points were recorded sequentially in one run for each combination of bar shape, angle of attack, wind velocity and being in front or behind the grid. A total of 96 complete set of measurements were obtained.

To measure the static pressure in front of and behind the grid, the static pressure ports of two Prandtl tubes, aligned with the flow direction, were used. Twelve measurement positions in front and behind the grid were tested (Fig. 3). The closest measurement point to the front of the grid was $110 \mathrm{~mm}$, and $85 \mathrm{~mm}$ to the back of the grid. Forty-eight pressure measurements were taken during the experiment for each combination of factors (bar shape, angle of attack and wind velocity), twenty-four measurements with a $y$-position aligned with the central grid bar and twenty-four aligned with the centre of the space between the two central grid bars. These two sampling lines were used to check if there was differences in the flow between and behind the grid bars. A total of 2304 pressure measurement points were recorded.

For measuring static pressures below $100 \mathrm{~Pa}$, a MKS Baratron 120AD pressure transducer (100 Pa measurement range, accuracy $+-0.12 \%$ of reading) from MKS instruments Inc. was used. Pressures exceeding $100 \mathrm{~Pa}$ were measured with a MKS Baratron 220DD pressure transducer (10 $\mathrm{kPa}$ measurement range, accuracy $+-0.15 \%$ of reading). At every measurement position the average was calculated for a sample period of 4 seconds at a sample frequency of $1200 \mathrm{~Hz}$.

Velocity measurements were conducted with a constant-temperature-anemometer (CTA) system of the type Multichannel CTA 54N81 from Dantec Dynamics AS (www.dantecdynamics.com). Two dual sensor-hot-wire probes, type 55P63 and 55P64, were used to record the velocities in front of and behind the grid. The velocity data were temperature corrected using the temperature probe 90P10.

The dual-sensor probes were oriented to obtain velocity information in the $x$ - and $z$-direction. As flow components in the $y$-direction biases readings, measurement positions were close to the $x$ - $z$ - 
symmetry plane and not at locations where the proximity of the grid affected the $y$-direction of the flow. Flow magnitude was calculated from the velocity readings as:

$$
|u|=\sqrt{u_{x}^{2}+u_{y}^{2}+u_{z}^{2}}
$$

with $u_{y}$ expected to be zero due to the position of the grid in relation to flow direction. In Fig. 4 , the starting point of the vectors showing the flow direction indicates the measurement positions. The closest distance between measurement positions and the front of the grid was $18 \mathrm{~mm}$. Due to a failure of the front probe, the measurement program had to be adjusted by using the back probe as the front probe. As a result, the closest distance to the grid was $35 \mathrm{~mm}$ for the investigations of Drop 8 and Cylindrical. Furthermore, only the measurement points with a coordinate $t \geq 0$ could be measured. The horizontal distance between the back of the grid and the closest measurement point was $85 \mathrm{~mm}$. A total of 82 CTA measurements were recorded for the Drop 4 and Rectangular grids, and 57 for the Drop 8 and Cylindrical grids in each $x$-z-measurement plane for the four angles of attack and the approaching velocities of $11.5,17.3$ and $23.1 \mathrm{~m} / \mathrm{s}$.

\subsection{Flow-through grids}

A grid is a resistance, $R$, to the flow as described by Laws and Livesey (1978) for gauze screens or by Blendermann (1987) for nettings and cables, expressed by

$$
R=\Delta p \cdot A_{\text {grid }}
$$

where $\Delta p$ is the pressure loss of the flow across the grid and $A_{\text {grid }}$ denotes the grids frontal area. When the grid is inclined to the flow, the flow is deflected toward the normal plane of the grid.

Assuming a steady inviscid and irrotational flow, and a normally oriented grid, the Rankine-Froude model (or actuator disc model; Gasch and Twele, 2011) and the Bernoulli equation may be adapted to allow for a general understanding of the flow properties in front of and behind the grid. 
Following the flow along a streamline towards the grid, assuming laminar flow, the relation between pressure and velocity in front of the grid can be expressed by the Bernoulli equation (neglecting the gravity term because the height level is constant),

$$
\frac{\rho}{2} \cdot u_{0}^{2}+p_{0}=\frac{\rho}{2} \cdot u_{1}^{2}+p_{1}=\text { constant }
$$

where the index 0 indicates the streamline position far in front of the grid, index 1 indicates the position in close proximity to the grid, and $\rho$ indicates the density of the fluid.

In the case of a stagnation point on a grid bar, the velocity $u_{1}$ is zero and it follows that

$$
\frac{\rho}{2} \cdot u_{0}^{2}+p_{0}=p_{1}
$$

$$
\frac{p_{1}-p_{0}}{\frac{\rho}{2} \cdot u_{0}^{2}}=1 .
$$

The static pressure coefficient is defined as

$$
c_{p}=\frac{p_{x}-p_{0}}{\frac{\rho}{2} \cdot u_{0}^{2}}
$$

where $p_{x}$ denotes the static pressure at location $x$. Thus, a $c_{p}=1$ implies that the flow in front of the grid stopped, while a $c_{p}$ value between 0 and 1 indicates a decreased flow velocity in comparison to the reference. In the experiments, the wind tunnel velocity $u_{0}$ and the ambient static pressure $p_{0}$ at the nozzle outlet were used as references.

Following the approach of the Rankine-Froude model, the grid is assumed to be of infinitesimally small depth, represented only by a pressure loss. Thus, the flow is uniform and one-dimensional behind the grid, and the Bernoulli equation for a streamline starting immediately behind the grid to a distance downstream may be written as

$$
p_{2}+\frac{\rho}{2} \cdot u_{2}^{2}=p_{0}+\frac{\rho}{2} \cdot u_{3}^{2}
$$


where the index 2 indicates the streamline position behind the grid and index 3 indicates the position further downstream where the ambient pressure $p_{0}$ is present. Since the grid is assumed to be of infinitesimally small depth, the position right in front of and just behind the grid are in one location. Further, mass conservation demands $u_{1}=u_{2}$ and by subtracting Eq. 9 from Eq. 6 it follows

$$
\left(p_{1}-p_{2}\right)=\Delta p=\frac{\rho}{2} \cdot\left(u_{0}^{2}-u_{3}^{2}\right)
$$

Since the grid is a resistance to the flow, the pressure loss $\Delta p$ across the grid is larger than zero and hence the velocity behind the grid is smaller than the approaching flow $u_{o}$. The velocity at the grid is obtained from equating Eq. 5, with the expression for the resistance $R$ being derived by the balance of axial momentum far up- and downstream of the grid

$$
R=\rho \cdot u_{2} \cdot A_{\text {grid }} \cdot\left(u_{0}-u_{3}\right) .
$$

Thus, the velocity is given by

$$
u_{1}=u_{2}=\frac{1}{2} \cdot\left(u_{0}+u_{3}\right) .
$$

Since the flow velocity $u_{3}$ further downstream of the grid is smaller than the approach velocity $u_{0}$, the velocity at the location of the grid will also be smaller. Inserting Eq. 12 in Eq. 6 and Eq. 9 and solving for the pressure $p_{1}$ and $p_{2}$, the flow properties in front of and behind the grid are:

$$
\begin{gathered}
p_{1}=p_{0}+\frac{\rho}{2} \cdot\left(u_{0}^{2}-u_{1}^{2}\right) \\
p_{2}=p_{0}-\frac{\rho}{4} \cdot\left(u_{0}^{2}+u_{0} \cdot u_{3}-u_{3}^{2}\right)
\end{gathered}
$$

Based on the above, it is expected that the flow approaching the grid is decelerated and the static pressure is increased above the ambient pressure level. Across the grid, a pressure drop occurs, and the pressure immediately behind the grid is below the ambient pressure $p_{0}$ at a velocity smaller than the approach velocity. With increasing distance to the grid, the static pressure recovers to the level of the ambient again, resulting in a further velocity decrease. Since the static 
pressure behind the grid is below the ambient, the pressure loss coefficient $c_{p}$ will be negative and will approach zero at a distance downstream.

The Rankine-Froude model is suitable to give a general understanding of the flow patterns and, as can be seen above, the pressure loss across the grid is a major property affecting the flow. Moreover, according to Eq. 5 the pressure loss, $\Delta p$, is the main variable describing the resistance components. Therefore, to understand the effect of different bar geometries, the assumption of an inviscid flow is not valid and a closer look on the resistance components is necessary. For the flow through and around the grid, two components are of major importance. First, the resistance due to surface friction and second, the form resistance which is occurring when the flow around the grid's components does not follow the components contour. The flow separates from the surface and forms a wake region where eddies are generated, which drain energy and reducing the pressure at the downstream side. With the pressure reduced on the downstream side, the form resistance increases. Thus, under the same flow conditions, a larger wake region implies a larger form resistance.

The flow through a grid is governed by its porosity (see Eq. 1). From the mass flow conservation, it follows

$$
u_{n \text { grid }}=\frac{u_{1 n}}{\beta}=\frac{u_{2 n}}{\beta}
$$

where $u_{n \text { grid }}$ denotes the average normal velocity in between the grid's bars. The components of the flow approaching and leaving the grid normally are denoted by $u_{1 n}$ and $u_{2 n}$, respectively. Since the form resistance as well as the frictional resistance are dependent on the flow velocity, it is expected that grids with low porosities have a higher resistance as the velocity in between the grid's bars is higher.

To be able to link the grid's hydrodynamics and its potential sorting capability, the tangential and normal flow components were calculated from the CTA datasets. The flow that passes normally 
through the grid is denoted by $u_{n}$ and is the flow which transports undersized catch through the grid. The upwards flow along the grid surface, the tangential flow, is denoted by $u_{t}$ and is the flow which transports catch along the grid. Only the measurement points closest to the grid surface were evaluated. To allow for comparison of the datasets, the tangential and normal flow components were normalized to the decomposed approaching flow $u_{0}$ (Fig. 3). Thus

$$
\begin{gathered}
u_{N}=\frac{u_{n}}{u_{n 0}}=\frac{u_{n}}{u_{0} \cdot \sin \alpha} \\
u_{T}=\frac{u_{t}}{u_{t 0}}=\frac{u_{t}}{u_{0} \cdot \cos \alpha}
\end{gathered}
$$

where $u_{N}$ and $u_{T}$ denote the relative velocities.

\section{Results}

A total of 2304 static pressure measurement points were obtained considering the different combinations of bar shape, grid angle and approaching velocity, while a total of 3336 velocity measurements from the CTA system were obtained. The reading of the wind tunnel velocity for the CTA measurement behind the Drop 8 grid, at an approaching flow of 3 knots equivalent and $60^{\circ}$ angle of attack was considered invalid after analysing the data and was therefore removed from the analysis.

The two static pressure datasets, one in line with the central bar of the grid and the other in line with the adjacent space between the bars, were obtained for all different combinations of grid angles, bar shapes and approaching velocities. Static pressure coefficient curves showed congruency with the expectation from the Rankine-Froude model presented above (Fig. $5 \mathrm{~A}$ and B). The static pressure increased ahead of the grid, decreased at the grid, and recovered to the original behind the grid. The overall pattern and value of the static pressure coefficient was independent of the approach velocity (Fig. 5), with a possible exception of values obtained for the Drop 8 grid at the $90^{\circ}$ angle (Fig. $5 \mathrm{~A}$ and supplement), where higher approach velocities showed 
slightly lower pressure values. Furthermore, no difference between the measurement points taken in line with the bar or between bars was observed for any bar shapes, angles of attack or approaching velocities. Local flow interferences due to the grid may be subsided at the distance of the measurement position closest to the grid. Due to these negligible differences between approach velocities, in the range of the investigated velocities, and relative position of the measurements, all subsequent results shown in this study will consider only the results for the approaching velocities equivalent to the towing speed of 3 knots (wind velocity of $17.3 \mathrm{~m} / \mathrm{s}$ ) and measured aligned with the central bar of each grid. The entire static pressure measurements are given in the supplementary material (Fig. S1, S2 and S3).

The static pressure coefficient $c_{p}$ in front of the grid was larger for the Drop 8 and Cylindrical grids than for the grids with higher porosity, at all investigated grid angles of attack (Fig. 6). The values for $c_{p}$ behind the grid were lower for the grids with lower porosity, implying that the pressure loss across the grids, and hence the resistance of the grids decreases with increasing porosity. There was no difference between the pressure field from the Drop 8 and Cylindrical grids. Grids Drop 4 and Rectangular with similar porosity, however, showed a difference (Fig. 6). The grid with the rectangular shaped bars induces the least increase of $c_{p}$ in front of the grid, whereas behind the grid, pressures were similar to that from Drop 4 (Fig. 6).

A flow acceleration on the top and bottom of the grid frame was observed for the two lower grid angles, $30^{\circ}$ and $45^{\circ}$ (Fig. $6 \mathrm{~A}$ and B). Since the flow has to pass around the frame it is locally accelerated, which results in a decrease of the static pressure, indicated by a dip on the $c_{p}$-curve. At lower angles, the distance between frame bars and the location of measurement is reduced and hence the effect is more distinct at lower angles. In addition, this effect is more pronounced in front of the grids with higher porosity since the flow in front of these grids is not as decelerated, resulting in higher velocities. 
Fig. 4 gives an overall view of the flow field measured by the CTA probes in front of and behind the Drop 4 grid at an angle of $60^{\circ}$ and with an approaching velocity equivalent to $3 \mathrm{kn}$. The overall flow pattern was similar to the one presented in Fig. 4 for all grids, velocities and grid angles of attack, except for the grid angle of $90^{\circ}$, where no deflection occurred. The magnitude of the velocity was scaled by the approaching flow velocity $u_{0}$ and is illustrated in Fig. 4 by a colour contour plot. The flow direction was indicated by vectors starting at the measurement position. As expected from theory, the flow velocity in front of the grid decreased and continued to decrease with increasing distance behind the grid. In front of the grid, there was a notable difference in the flow velocity along the bars. In close proximity to the bottom cross member of the grid's frame the velocity increased, whereas near the upper cross member the velocity decreased. The flow through the grid decreased in the upper region because the flow field might have been affected by the flow stagnation in front of the upper bar of the grid frame. For the velocity increase in the lower part, the flow might have split at the edge of the lower bar of the grid frame, causing the emerging wake region to constrict the flow, which results, according to the law of mass flow balance, in an increase of the flow velocity.

The flow is slightly deflected upwards in front of the grid (Fig. 4). At the measurement points closest to the back of the grid the deflection was reduced in comparison to the front. The strongest change in flow direction was measured at the position farthest downstream (distance grid measurement point $735 \mathrm{~mm}$ ). However, the results of a numerical flow simulation (unpublished manuscript) show that this strong change in direction was attributed to the wake of the bars from the grid frame.

The flow velocity along the front of the grid $\left(u_{t}\right)$, was less affected by the grid's inclination (Fig. 7). Furthermore, the magnitude of the flow component is in the order of that from the tangential flow component of the approaching flow $\left(u_{t 0}=u_{0} \cdot \cos \alpha\right)$, i.e. around 1 . Thus based on the measurements obtained here, a "rule of thumb" for the flow along the grid which transports the catch, may be given by 


$$
u_{t}=u_{0} \cdot \cos \alpha .
$$

All grid configurations showed a decrease in the tangential component immediately behind them in relation to the tangential component immediately in front, with the Drop 4 grid showing the lowest reduction. The Drop 4 grid showed an average decrease of $3.4 \%( \pm 1.6 \%$, standard deviation), while the Rectangular grid showed an average decrease of $6.3 \%( \pm 3.2 \%)$, Drop $85.5 \%( \pm 1.4 \%)$, and Cylindrical $7.8 \%( \pm 1.7 \%)$.

Inspecting the plots of the velocity' normal component of the velocity (Fig. 7), it can be noted that it is of the same magnitude in front of and behind the grids. This was expected due to the conservation of the mass flow through the grid. The grids with lower porosity (Cylindrical and Drop 8) showed a reduction of around $30 \%$ in the velocity' normal component in relation to the normal component of the approach velocity. A lower relative reduction of around $10 \%$ was observed for the grids with higher porosity (Rectangular and Drop 4). Thus, the normal component can be approximated, as a "rule of thumb", by

$$
\begin{gathered}
u_{n}=0.7 \cdot u_{0} \cdot \sin \alpha \text { for grids with a porosity of } 0.4 \text { and } \\
u_{n}=0.9 \cdot u_{0} \cdot \sin \alpha \text { for grids with a porosity of } 0.6 \text {. }
\end{gathered}
$$

The normal component of the flow, which passes through the grid and should transport the undersized catch, was slightly higher at lower angles. At lower angles, the intersection of a plane spanned by the $y$-axis and the flow direction at the grid's bar results in a more elongated crosssection shape of the bar that the flow has to follow. For example, at $90^{\circ}$ the cross-section of the cylindrical bar is circular, while at lower angles this cross-section shape becomes an elliptical shape that will be more and more elongated as the angle of attack lowers. Thus, the form resistance decreases with decreasing grid angle and, therefore, allowing for a higher flow velocity at lower angles.

\section{Discussion}


The results presented here show that grid porosity is an important factor to consider when designing or selecting a sorting grid for a given fishery. At low porosity values, the water is simply rejected by the grid, thus greatly reducing the water flow through the grid. Using two values for porosity as an example, clarifies what the effects of it are on gear selectivity. A porosity of zero represents a solid plane, whereas a porosity of 1 implies that no grid is present. The improved hydrodynamic performance of grids with higher porosity have also been described by Riedel and DeAlteris (1995) and Grimado (2006).

Porosity, followed by bar shape, affected the hydrodynamics of flow near and around the grid. The overall similarity in the results obtained between the Drop 8 and Cylindrical bars showed that the drop shape was not designed properly. Indeed, blunt bodies with a high width-to-length ratio cause a high form resistance since the flow will separate from the body surface forming a wake region. Contrary, streamlined bodies with a low width-to-length ratio produce a low form resistance since the flow follows the body surface. The width-to-length ratio of the drop shape bars was too high to have a positive effect on the resistance. The flow separation may have taken place at a similar area as on the cylindrical grid bar, resulting in a similar resistance. Furthermore, the separation of flow was enhanced by a small edge at the change from the cylindrical head to the tapered flank of the drop, rendering the shape inefficient. It is recommended that care should be taken during the production of the grid bars to achieve a smooth surface and smooth transitions between shapes. A somewhat unexpected result was that the grid with the rectangular bars performed best. However, this could be due to the highest porosity of this grid, the width-to-length ratio being 3.3 times lower than for the Drop 4 grid, and due to the wake region of the rectangular bars potentially being smallest

The angle of attack showed to be less important than the porosity in affecting the flow. However, it is an important variable which needs to be carefully tuned to achieve intended effectiveness. The static pressure measurements at lower grid angles show a lower increase of static pressure in front of the grid and a higher flow in front of the grid. However, since the investigated grids had a fixed 
height, the area that faced the flow decreased with decreasing inclination, thus resulting in a smaller overall resistance to the flow. The lower static pressure in front of the grids may be due to the changed surface contour, but to the smaller overall area that faces the flow at lower grid angles. Further investigations have to be carried out to provide clarification.

Towing velocity showed to have nearly no effect on the hydrodynamic performance within the investigated range. The range of investigated velocities was based on the towing speeds commonly observed in commercial crustacean demersal trawl fisheries. Riedel and DeAlteris (1995) also reported a negligible effect of flow velocity on the grid's hydrodynamics, even though lower velocities (between 1 to 2 knots) were tested in that study.

Aside from hydrodynamics, the sorting performance of a grid may also depend on the physical and behavioural characteristics of the target species. For the shrimp fishery, the flow through the grid is highly relevant since shrimps are passive inside the trawl, being transported mostly by the water flow (Polet, 2002; He and Balzano, 2012). This is especially true for brown shrimps, as fatigue sets in after around 15 tail-flips (Hagerman and Szaniawska, 1986), where for each tail flip, swimming speeds (0.4 to $1.1 \mathrm{~m} . \mathrm{s}-1)$, and distances covered per tail flip (20 to $80 \mathrm{~mm}$ ) are limited (Arnott et al., 1998). Thus, it is likely that brown shrimp have little to no swimming capacity when close to the codend. Therefore, a flow too strong through a grid, coupled with too little flow being deflected along the grid's surface, can potentially lead to loss of commercial sized catch. Individuals of lengths close to the upper limit of the sorting range may pass through the bars due to the strong flow. If a good balance between flows through and along the grid exists, these individuals will be pushed along the grid surface towards the opening of the grid. Furthermore, a strong flow through the grid might also cause clogging issues due to part of the catch becoming stuck to the grid bars without being able to move. On the other hand, if the flow along the grid surface is too high, the sorting capacity of the grid will be affected, since small shrimps would simply be entrained by the flow towards the codend without contacting the grid. The results obtained here, allowed presenting a "rule of thumb" for the calculation of flow velocities of the normal and tangential components in 
front of the grid dependent on an approaching flow velocity and the grids angle of attack. However, further research is needed to obtain information about the interaction of shrimp, flow velocities and sorting grid designs to be able to find the optimal balance between the flow through and along the grids surface.

In our experiment, the flow through the system was homogenous and only affected by the grid. In contrast, when mounted inside a trawl, the flow velocity approaching the grid will not be the same as the flow entering the mouth of the trawl. This may especially be true for fisheries where sieve nets are used. Sieve nets are panels with a large mesh placed inside the trawl to guide large bycatch species and debris towards an outlet. These by-catch reduction devices will reduce the flow that continues towards the codend, since it directs part of the flow to the outlet (Polet et al., 2004). Another modification usually associated with grids is a guiding or lifting panel, which usually consists of small mesh netting used to guide the catch towards the grid to maximize contact probability. It has previously been shown that the water flow is greatly reduced due to this small mesh netting (Gjøsund et al., 2013).

A further issue affecting the flow field in front of the grid is the netting surrounding it, which may prevent free flow around the sorting grid, affecting the flow in front of and behind it. This knowledge is critical to the adjustment of the sorting grid effectiveness. Unfortunately, the extent surrounding netting, sieve net, and guiding panel alter the flow field in front of the net has not been investigated.

Due to various interacting factors, a recommendation as to the best design for various fisheries should be given on a case-by-case basis. However, our results show that, in general, low porosity grids should be avoided, since the flow through and in front of it will decrease. Thus, low porosity might reduce the sorting capabilities of a grid and increase the probability of it becoming clogged. Furthermore, the selective performance of further selective devices inside a trawl positioned after a grid will be negatively affected when the flow that passes through the first grid is too low, as reported for duals grid systems (He and Balzano, 2012; Larsen et al., 2018). If grid efficiency is 
assessed solely according to hydrodynamics, the Rectangular grid performs best. However, even though the Drop 4 grid has slightly less desired hydrodynamics than the Rectangular grid, it may still perform better as a fishing selective device. The minimum bar spacing of $6 \mathrm{~mm}$ is reached only at the position of maximum bar width for the drop shape bar, whereas for the Rectangular bar the minimum bar spacing is maintained nearly along the full bar depth. This means that the likelihood for the catch to get stuck between the bars might be less for the drop shape, thus decreasing the probability of clogging issues. In addition, when the rectangular shaped grid bars are not aligned with the flow, side forces may occur and reduce sorting efficiency. Moreover, the drop-shaped bars, when compared to cylindrical bars, add structural strength due to its elongated shape, which is important when considering thinner bar diameters.

Another important aspect is the width and shape of the bars tested. Thicker bars, together with the shape of the leading edge, may help guide the shrimp through the grid, whereas thinner bars result in more grid bars per total grid width. This higher bar per grid ratio adds more points of contact for a shrimp to be held onto when it reaches the front face of the grid in a crosswise position. Even though it is important to understand specific characteristics of a grid such as hydrodynamic performance, when designing and mounting a grid in a trawl it is also important to consider all other factors mentioned above. This study shed light on different aspects of grid hydrodynamics, providing a "rule of thumb" for flow velocities of the normal and tangential components ahead of the grid. Following a discussion with the fishing industry (e.g. netmakers and fishermen) of the results here obtained, it was decided that bars with drop shape and $4 \mathrm{~mm}$ width (Drop 4) showed to have the potential to be used in the fishery. Thus, a grid with similar dimensions to the ones tested here, with $6 \mathrm{~mm}$ bar spacing, and with Drop 4 shaped bars will be tested in the fishery as an alternative to the $26 \mathrm{~mm}$ diamond mesh codend as a way to reduce the catch of small shrimp.

\subsection{Future work}


In future studies, the interaction between shrimps and grids should be analyzed. When and how do shrimps become stuck? Which bar shapes guide the shrimp best? Which minimum flow velocity along the grid is required so that shrimps of a given size are transported along? These questions have to be answered to find an optimal balance between the flow through and along the grid and hence the optimal inclination of the grid.

In addition, the effects of extra guiding and filtering nettings of trawls should be examined. For the purpose of the development predictive numerical flow simulations for the grids, which may provide insights into the interaction of trawl grid and netting, it is necessary to establish loading functions describing the hydrodynamic characteristic of grids. Furthermore, field tests of the results obtained here are also important to better relate the hydrodynamics of grids from laboratory settings to field conditions.

\section{Acknowledgements}

This study was funded by the European Maritime project Fast-Track - Sustainable, cost effective and responsive gear solutions under the landing obligation, grant number 33112-P-15-013. The authors would like to thank the reviewers for their valuable comments and suggestions that helped to improve the quality of the manuscript. 


\section{References}

Arnott, S.A., Neil, D.M. and Ansell, A.D., 1998. Tail-flip mechanism and size-dependent kinematics of escape swimming in the brown shrimp Crangon crangon. J. Exp. Biol. 201(11): 1771-1784.

Blendermann, W., 1987. An analysis of the hydrodynamic forces on cables and nets. Appl. Ocean. Res. 9 (4): 224-33. doi:10.1016/0141-1187(87)90004-6.

Catchpole, T.L. and Revill, A.S., 2008. Gear technology in Nephrops trawl fisheries. Rev. Fish. Biol. Fisheries 18(1): 17-31. doi:10.1007/s11160-007-9061-y

Eayrs, S., 2007. A guide to bycatch reduction in tropical shrimp-trawl fisheries. FAO Revised edition. Rome, 108 p.

Fridman, A. L., 1986. Calculations for fishing gear designs. FAO, ISBN 0-85238-141-7

Gasch, R., \& and Twele, J. (Eds.). (2011). Chapter 5 in: Wind power plants: fundamentals, design, construction and operation. Springer Science \& Business Media, DOI doi:10.1007/978$3-642-22938-1$.

Gjøsund, S.H., Grimaldo, E., Sistiaga, M., Hansen, K., 2013. Hastighetsmålinger i 2- og 4panel enkeltristseksjoner (Velocity measurements in 2- and 4-panelsingle grid sections). In: SINTEF Fisheries and Aquaculture Report A24698.Trondheim, ISBN 978-82-14-05641-9.

Graham, N. 2010. Technical measures to reduce bycatch and discards in trawl fisheries. In Behaviour of marine fishes: capture processes and conservation challenges. Edited by $\mathrm{P}$. He. Wiley-Blackwell, Ames, lowa. pp. 239-264. doi:10.1002/9780813810966.ch10

Grimaldo, E. and Larsen, R.B., 2005. The cosmos grid: A new design for reducing by-catch in the Nordic shrimp fishery. Fish. Res. 76(2): 187-197. doi:10.1016/j.fishres.2005.06.010 
Grimaldo, E., 2006. The effects of grid angle on a modified Nordmøre-grid in the Nordic Shrimp Fishery. Fish. Res. 77(1): 53-59. doi:10.1016/j.fishres.2005.09.001

Grimaldo, E., Sistiaga, M., Herrmann, B., Gjøsund, S.H. and Jørgensen, T., 2015. Effect of the lifting panel on selectivity of a compulsory grid section (Sort-V) used by the demersal trawler fleet in the Barents Sea cod fishery. Fish. Res. 121: 158-165. doi:10.1016/j.fishres.2015.05.028Hagerman, L. and Szaniawska, A., 1986. Behaviour, tolerance and anaerobic metabolism under hypoxia in the brackish-water shrimp Crangon crangon. Mar. Ecol. Prog. Ser. 34: 125-132.

He, P. and Balzano, V., 2012. The effect of grid spacing on size selectivity of shrimps in a pink shrimp trawl with a dual-grid size-sorting system. Fish. Res. 121: 81-87. doi:10.1016/j.fishres.2012.01.012

ICES. 2016. Interim Report of the Working Group on Crangon Fisheries and Life History (WGCRAN), 23-25 May 2016, Oostende, Belgium. ICES CM 2016/SSGEPD:07. 33 pp.

Isaksen, B., Valdemarsen, J.W., Larsen, R.B. and Karlsen, L., 1992. Reduction of fish by-catch in shrimp trawl using a rigid separator grid in the aft belly. Fish. Res. 13(3): 335-352. doi:10.1016/0165-7836(92)90086-9

Kvalsvik, K., Huse, I., Misund, O.A. and Gamst, K., 2006. Grid selection in the North Sea industrial trawl fishery for Norway pout: Efficient size selection reduces bycatch. Fish. Res. 77(2): 248-263. doi:10.1016/j.fishres.2005.10.002

Kvalsvik, K., Misund, O.A., Engås, A., Gamst, K., Holst, R., Galbraith, D. and Vederhus, H., 2002. Size selection of large catches: using sorting grid in pelagic mackerel trawl. Fish. Res. 59(1-2): 129-148. doi:10.1016/S0165-7836(01)00408-8

Larsen, R.B., Herrmann, B., Sistiaga, M., Grimaldo, E., Tatone, I. and Onandia, I., 2016. Size selection of redfish (Sebastes spp.) in a double grid system: Estimating escapement through 
individual grids and comparison to former grid trials. Fish. Res. 183: 385-395. doi:10.1016/j.fishres.2016.07.013

Larsen, R.B., Herrmann, B., Sistiaga, M., Grimaldo, E., Tatone, I. and Brinkhof, J., 2018. Size selection of cod (Gadus morhua) and haddock (Melanogrammus aeglefinus) in the Northeast Atlantic bottom trawl fishery with a newly developed double steel grid system. Fish. Res. 201: 120-130. doi:10.1016/j.fishres.2018.01.021

Laws, E. M. and Livesey, J. L., 1978. Flow through screens. Ann. Rev. Fluid Mech. 10:, pp. 247-66. doi:10.1146/annurev.fl.10.010178.001335

Lövgren, J., Herrmann, B. and Feekings, J., 2016. Bell-shaped size selection in a bottom trawl: A case study for Nephrops directed fishery with reduced catches of cod. Fish. Res. 184: 26-35. doi:10.1016/j.fishres.2016.03.019

Maurstad, E., 1997. Selektivt trålfiske etter dypvannsreker (Pandalus borealis Krøyer, 1938). Etablert teknologi vurdert opp mot ny type skillerist. Fiskerikandidatoppgave i fiskeriteknologi. Norges fiskerihøgskole. Universitetet i Tromsø. FISK: 252, 84 pp. (in Norwegian)

Mellibovsky, F., Prat, J., Notti, E. and Sala, A., 2015. Testing otter board hydrodynamic performances in wind tunnel facilities. Ocean Eng. 104: 52-62. doi:10.1016/j.oceaneng.2015.04.064

Mellibovsky, F., Prat, J., Notti, E. and Sala, A., 2018. Otterboard hydrodynamic performance testing in flume tank and wind tunnel facilities. Ocean Eng. 149: 238-244. doi: 10.1016/j.oceaneng.2017.12.034

MSC, 2017. Public Certification Report North Sea Brown Shrimp. Marine Stewardship Council certification, 2017. 428 pp. https://fisheries.msc.org/en/fisheries/north-sea-brownshrimp/@@assessments accessed in October, 2018 
Paschen, M., Winkel, H.J. and Knuths, H., 2008. Fluid-structure interactions in pelagic trawls and probable consequences for the selectivity of the fishing gear. Advances in Science and Technology 58: 247-256. doi: doi.org/10.4028/www.scientific.net/AST.58.247

Polet, H., 2002. Selectivity experiments with sorting grids in the North Sea brown shrimp (Crangon crangon) fishery. Fish. Res. 54(2): 217-233. doi:10.1016/S0165-7836(00)00289-7

Polet, H., Coenjaerts, J. and Verschoore, R., 2004. Evaluation of the sieve net as a selectivityimproving device in the Belgian brown shrimp (Crangon crangon) fishery. Fish. Res. 69(1): 3548. doi:10.1016/j.fishres.2004.04.007

Reite, K.J. and Sorensen, A.J., 2006. Mathematical modeling of the hydrodynamic forces on a trawl door. IEEE J. Oceanic Eng. 31(2): 432-453. doi:10.1109/JOE.2006.875098

Riedel, R. and DeAlteris, J., 1995. Factors affecting hydrodynamic performance of the Nordmøre Grate System: a bycatch reduction device used in the Gulf of Maine shrimp fishery. Fish. Res. 24(3): 181-198. doi:10.1016/0165-7836(95)00375-K

Sistiaga, M., Brinkhof, J., Herrmann, B., Grimaldo, E., Langård, L. and Lilleng, D., 2016. Size selective performance of two flexible sorting grid designs in the Northeast Arctic cod (Gadus morhua) and haddock (Melanogrammus aeglefinus) fishery. Fish. Res. 183: 340-351. doi:10.1016/j.fishres.2016.06.022

Valdemarsen, J.W., 1989, November. Size selectivity in shrimp trawls. In Proceedings of the world symposium on fishing gear and fishing vessel design (pp. 39-41). St John's, Newfoundland: Institute of Fisheries and Marine Technology. pp. 39-41

Ward, J. N. and Ferro, R. S. T., 1993. A comparison of one-tenth and full-scale measurements of the drag and geometry of a pelagic trawl. Fish. Res. 17: 311-331. doi:10.1016/01657836(93)90132-Q 


\section{List of figures}

Figure 1. Technical sketch of grid and grid bar dimensions.

Figure 2. Schematic view of the grid in the test section (left panel). Test arrangement in the wind tunnel's test section (right panel).

Figure 3. Grid measurement coordinate system for the x-z-symmetry plane. Black crosses indicate the positions of the static pressure measurements.

Figure 4. Grid Drop 4 at $60^{\circ}, u_{-} 0 \approx 17.3 \mathrm{~m} / \mathrm{s}$ (equivalent to $\sim 3 \mathrm{kn}$ ). $2 \mathrm{D}$ vector and velocity contour plot. Vectors point in the direction of the flow, colour contours represent the magnitude of velocity scaled by the approaching flow velocity $u_{0}$.

Figure 5. Static pressure coefficient $c_{p}$ at different distances in front $(x<0)$ and behind $(x>0)$ the grid surface ( $x=0$, marked by the vertical dotted line). Grid angle $60^{\circ}$.

Figure 6. Static pressure coefficient at different distances in front $(x<0)$ and behind $(x>0)$ the grid surface $(x=0$, marked by the vertical dotted line) for the approaching velocity of $\approx 17.3$ m.s1 and aligned with the central bar of the grid for the four grid angles.

Figure 7. Tangential $\left(u_{T}\right)$ and normal $\left(u_{N}\right)$ velocity components at different positions along the grid. Position along the grid $t=0$ is the centre of the grid. 
Click here to download high resolution image
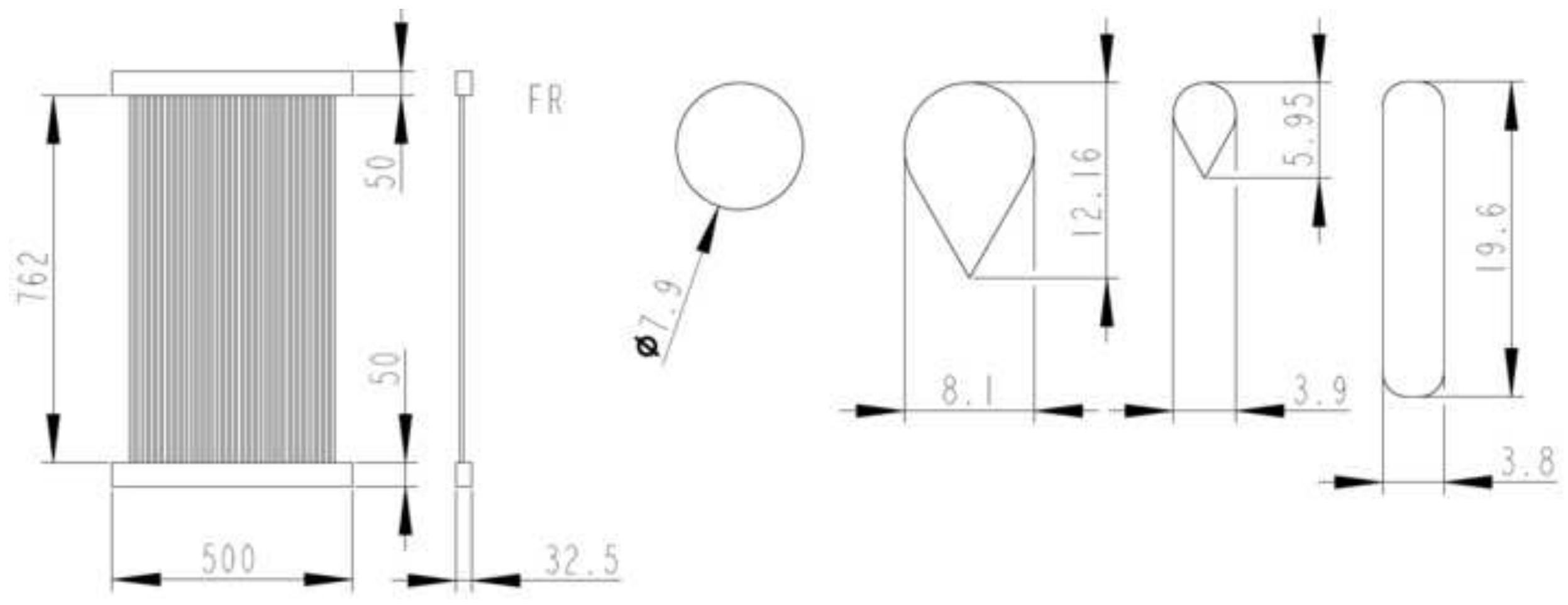


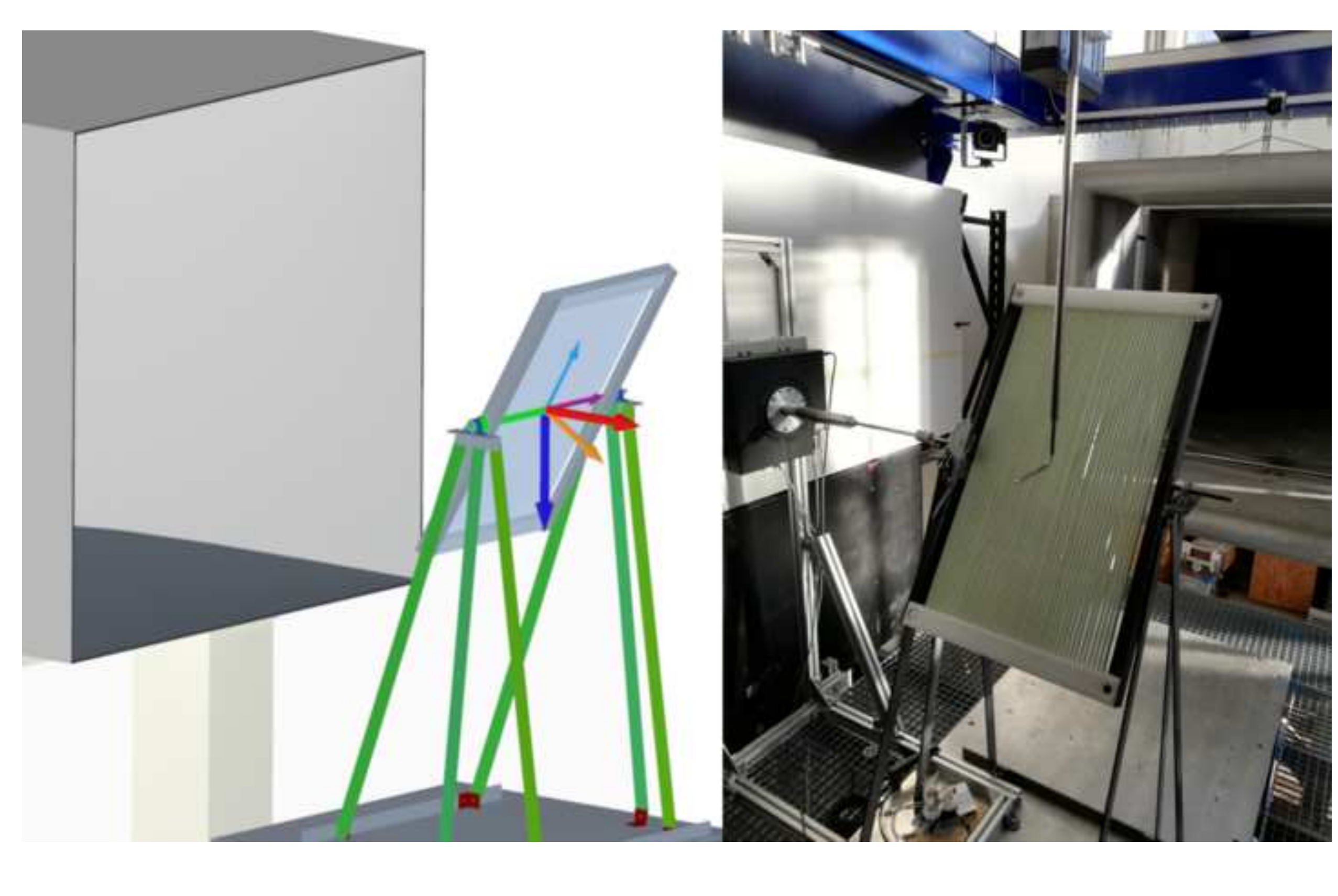

click here to download high resolution image

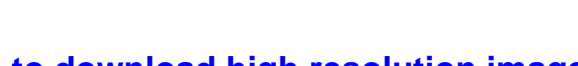

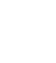

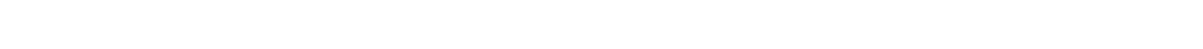

P
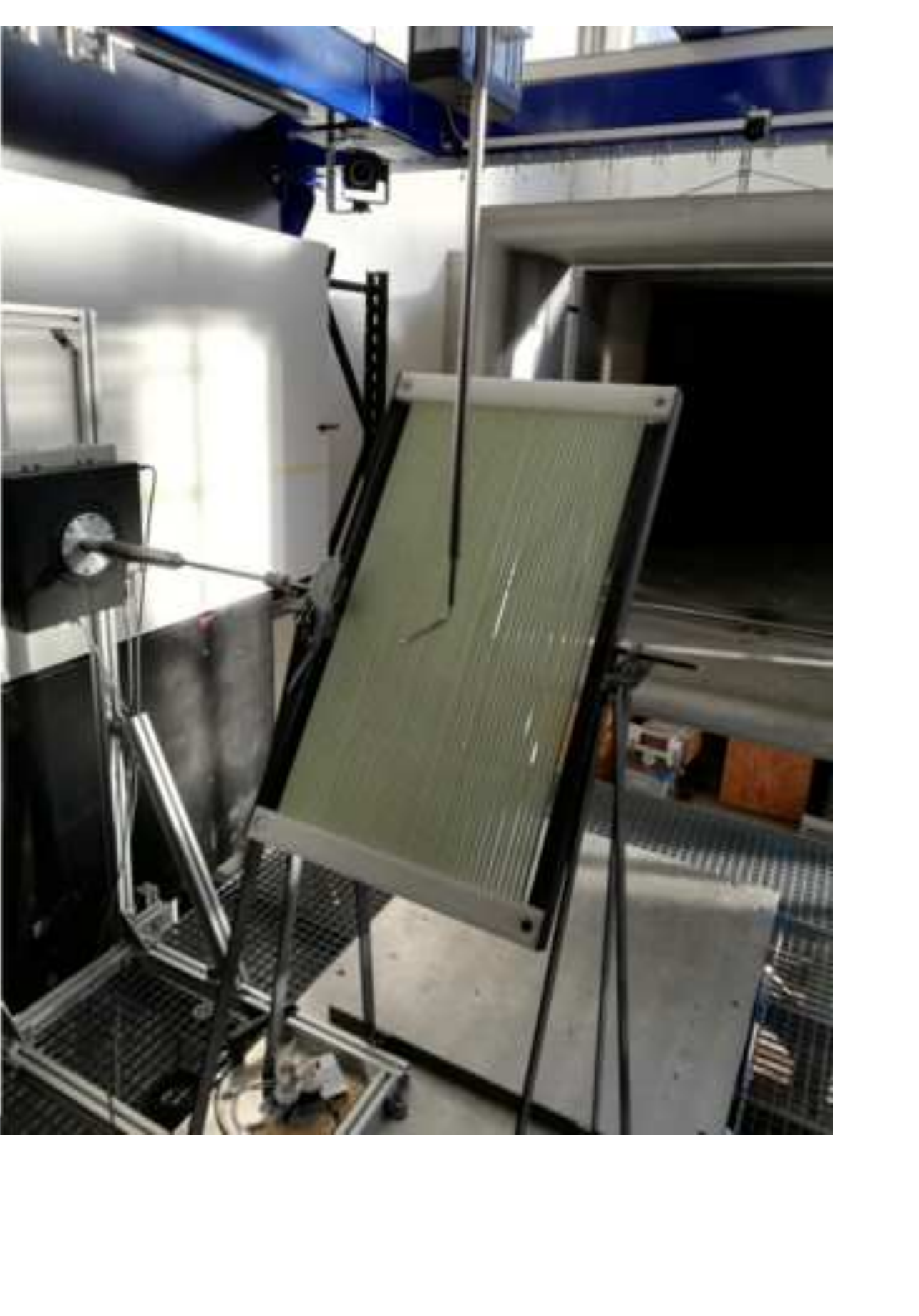
Click here to download high resolution image

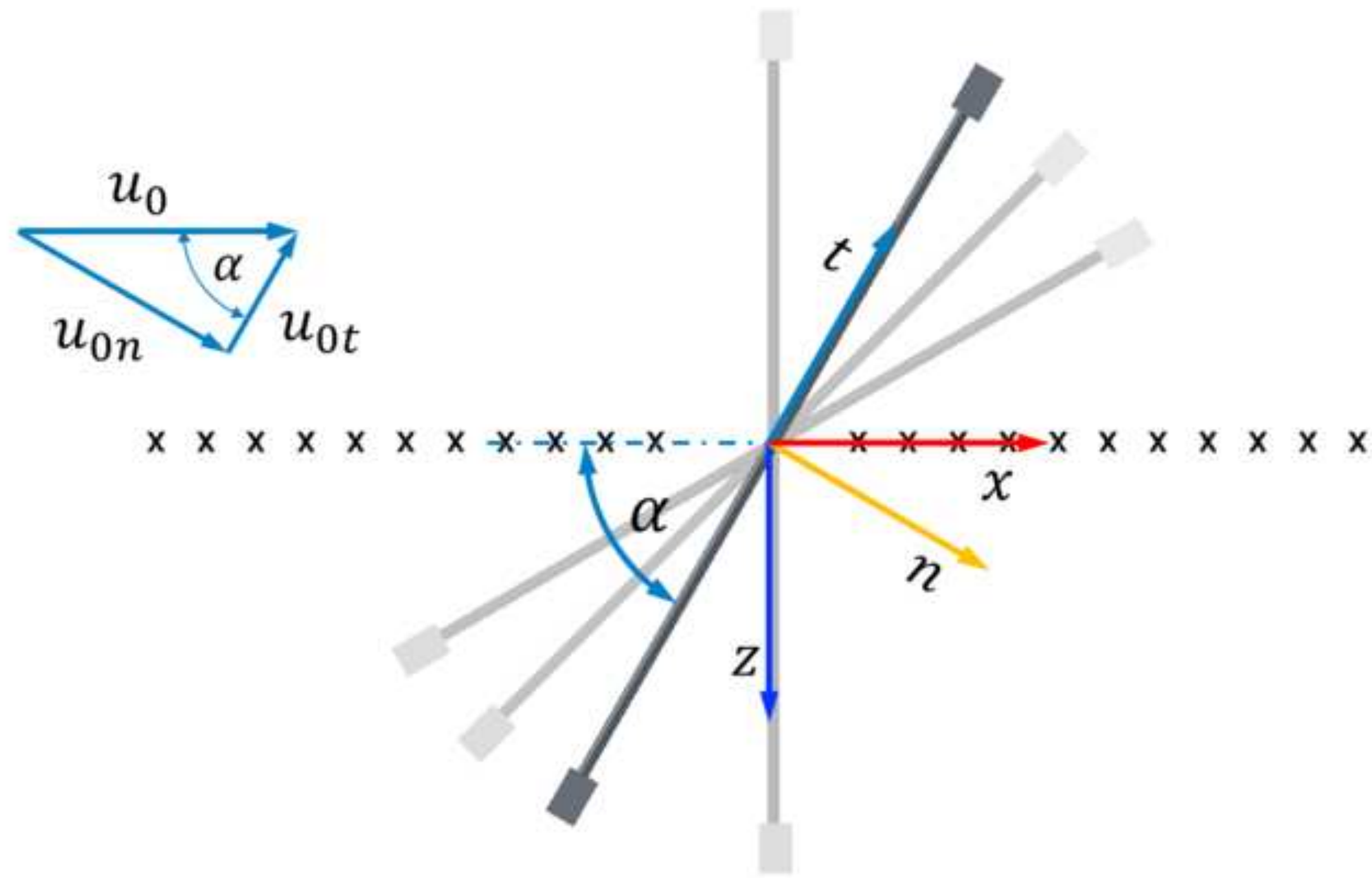




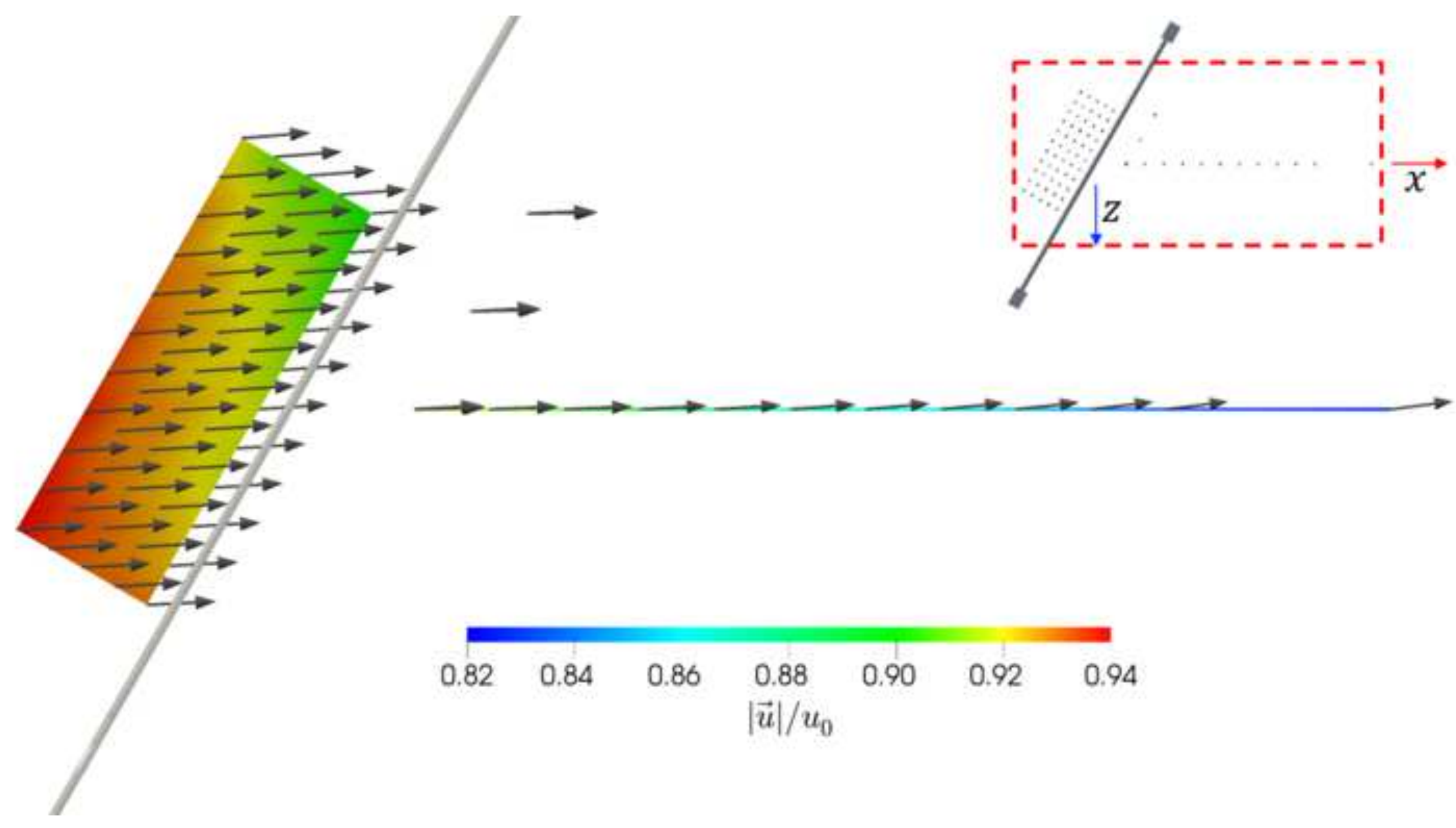


Click here to download high resolution image
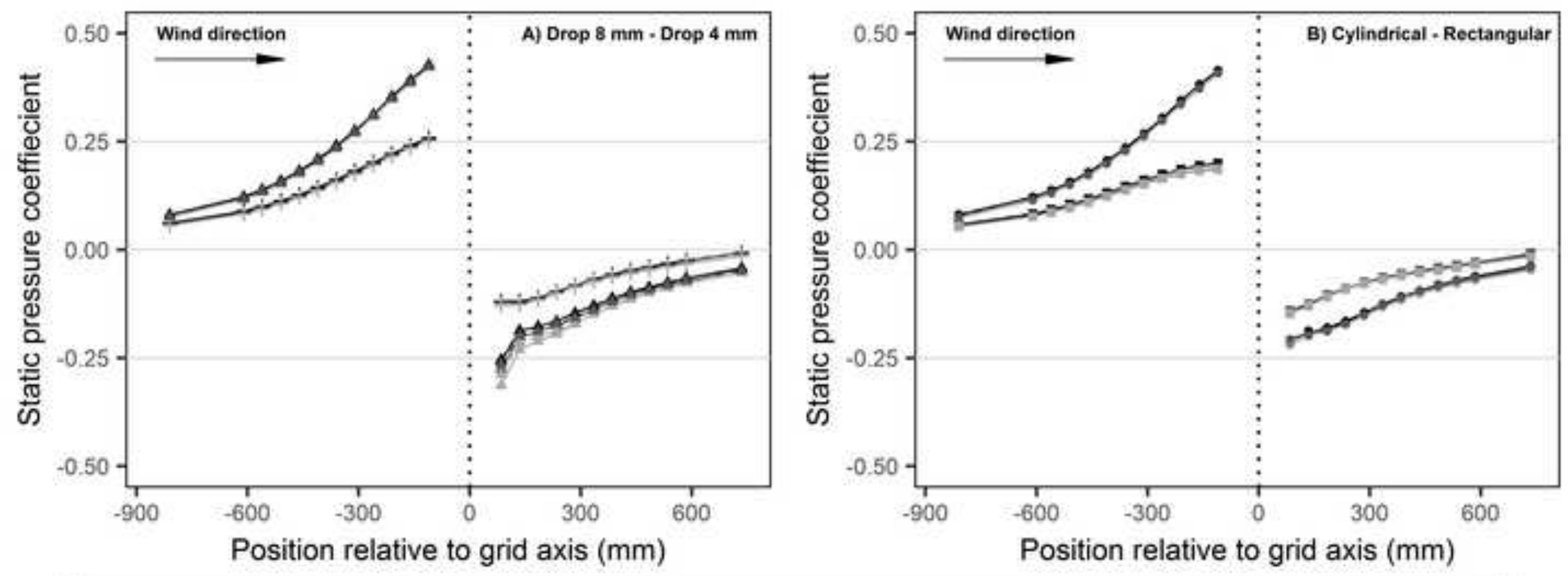

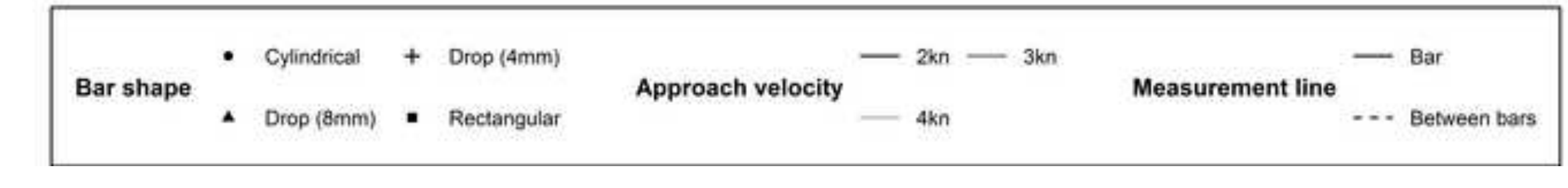


Click here to download high resolution image
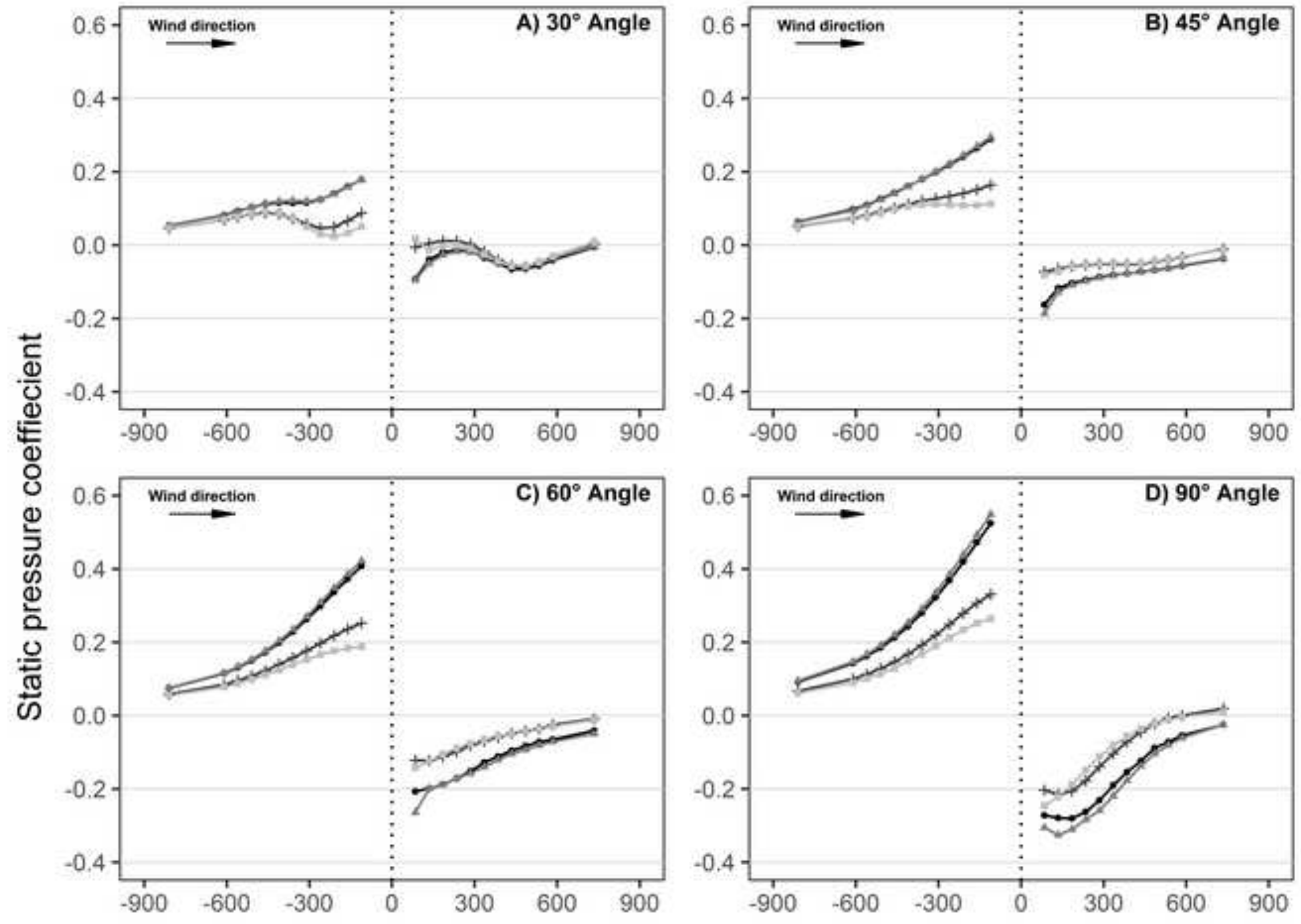

Position relative to grid $(\mathrm{mm})$

Grid $\rightarrow$ Cylindrical $\rightarrow \operatorname{Drop}(4 \mathrm{~mm}) \div \operatorname{Drop}(8 \mathrm{~mm}) \rightarrow$ Rectangular 


\section{Figure 7}

Click here to download high resolution image

Tangential velocity

Normal velocity

Cylindrical
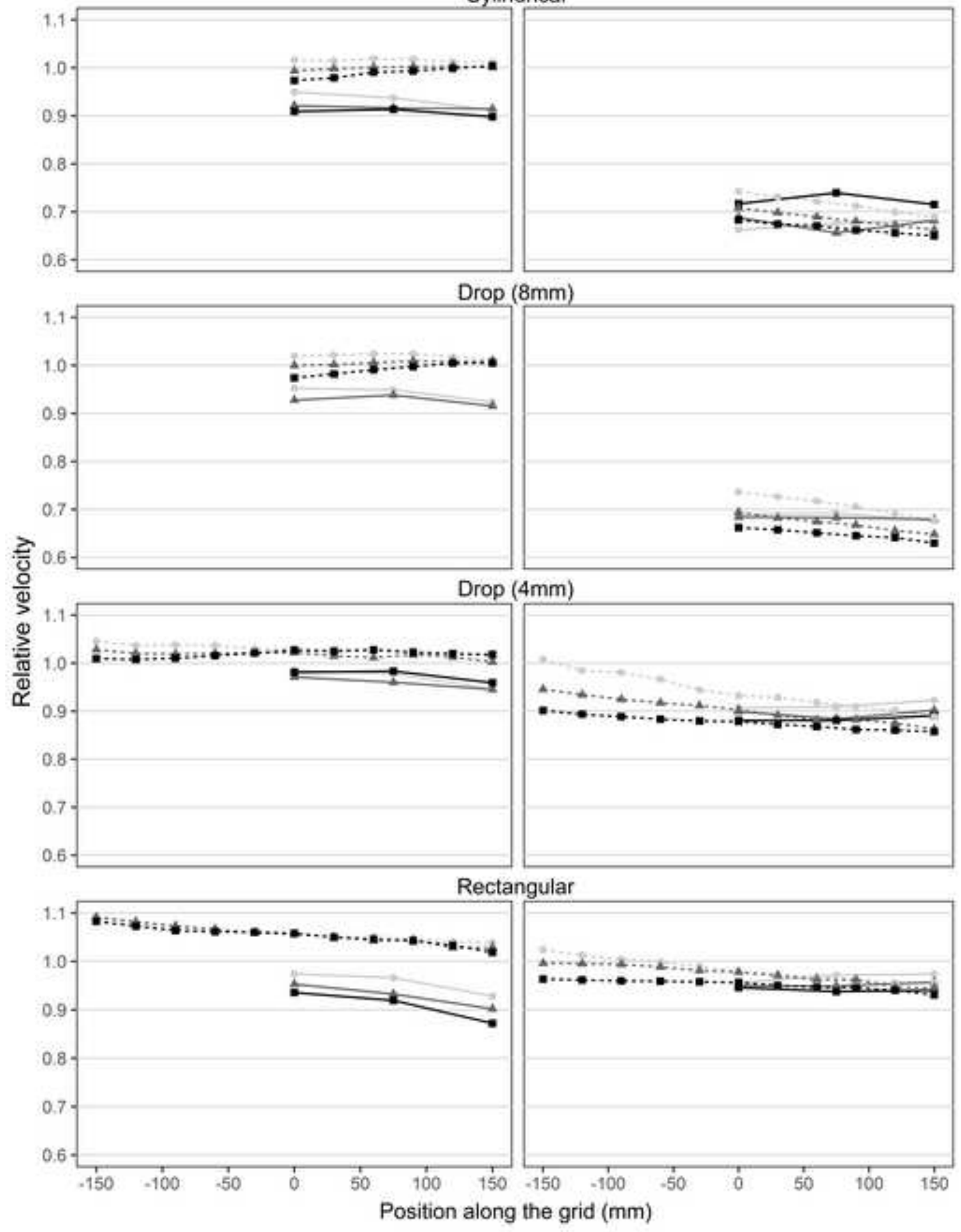

Relative position - back $\cdots$. front Grid angle $\rightarrow 30 \div 45 \rightarrow 60$ 
1 Supplementary material
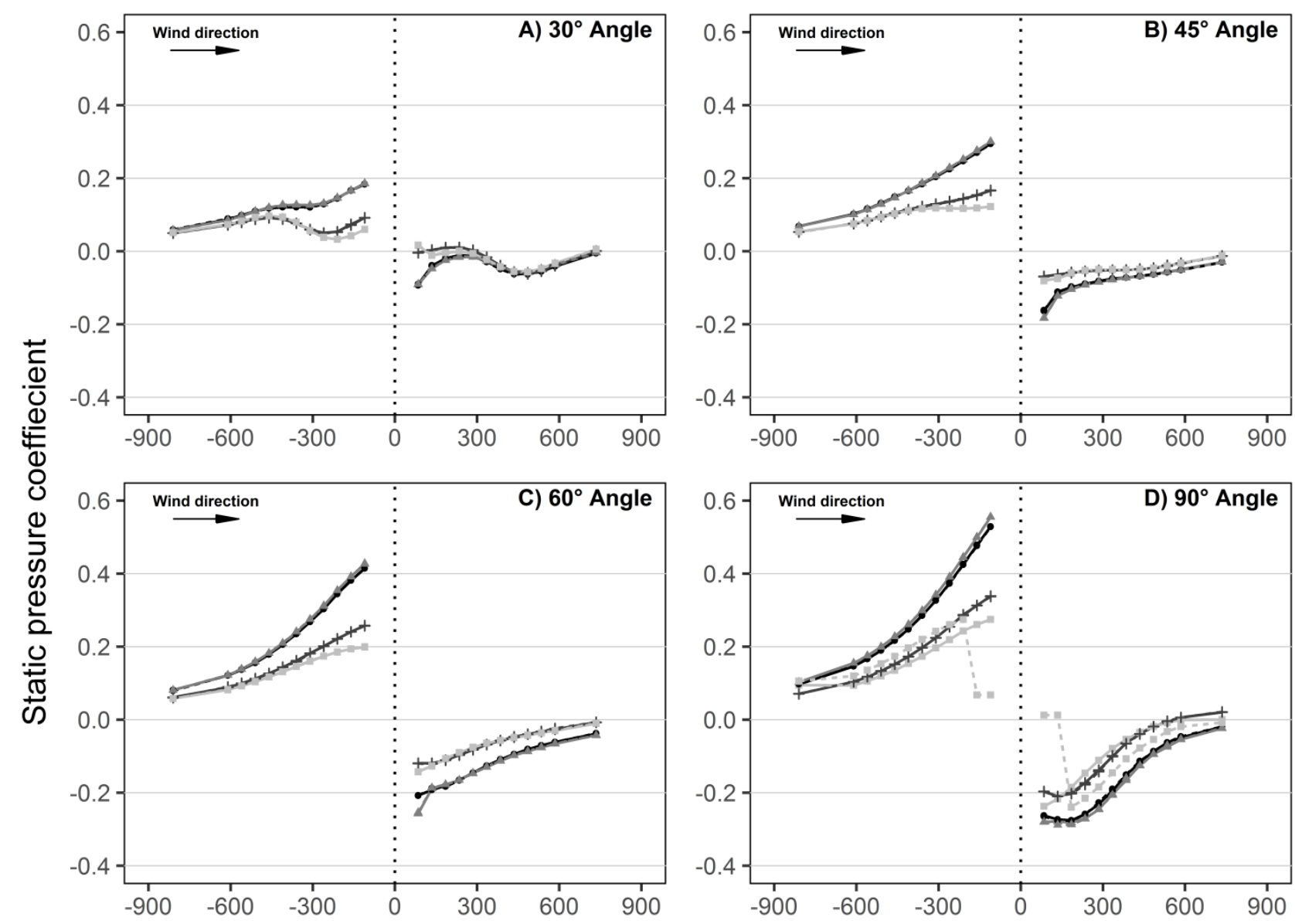

Position relative to grid $(\mathrm{mm})$

Grid $\rightarrow$ Cylindrical $\longrightarrow$ Drop $(4 \mathrm{~mm}) \longrightarrow$ Drop $(8 \mathrm{~mm}) \longrightarrow$ Rectangular Line Pos. - Bar_Line -... BetweenBars_Line

Figure S1. Static pressure coefficient at different distances in front $(x<0)$ and behind $(x>0)$ the grid surface $(x=0$, marked by the vertical dotted line) for the approaching velocity of $\approx 11.5 \mathrm{~m}^{-1}$ and aligned with the central bar of the grid for the four grid angles. 

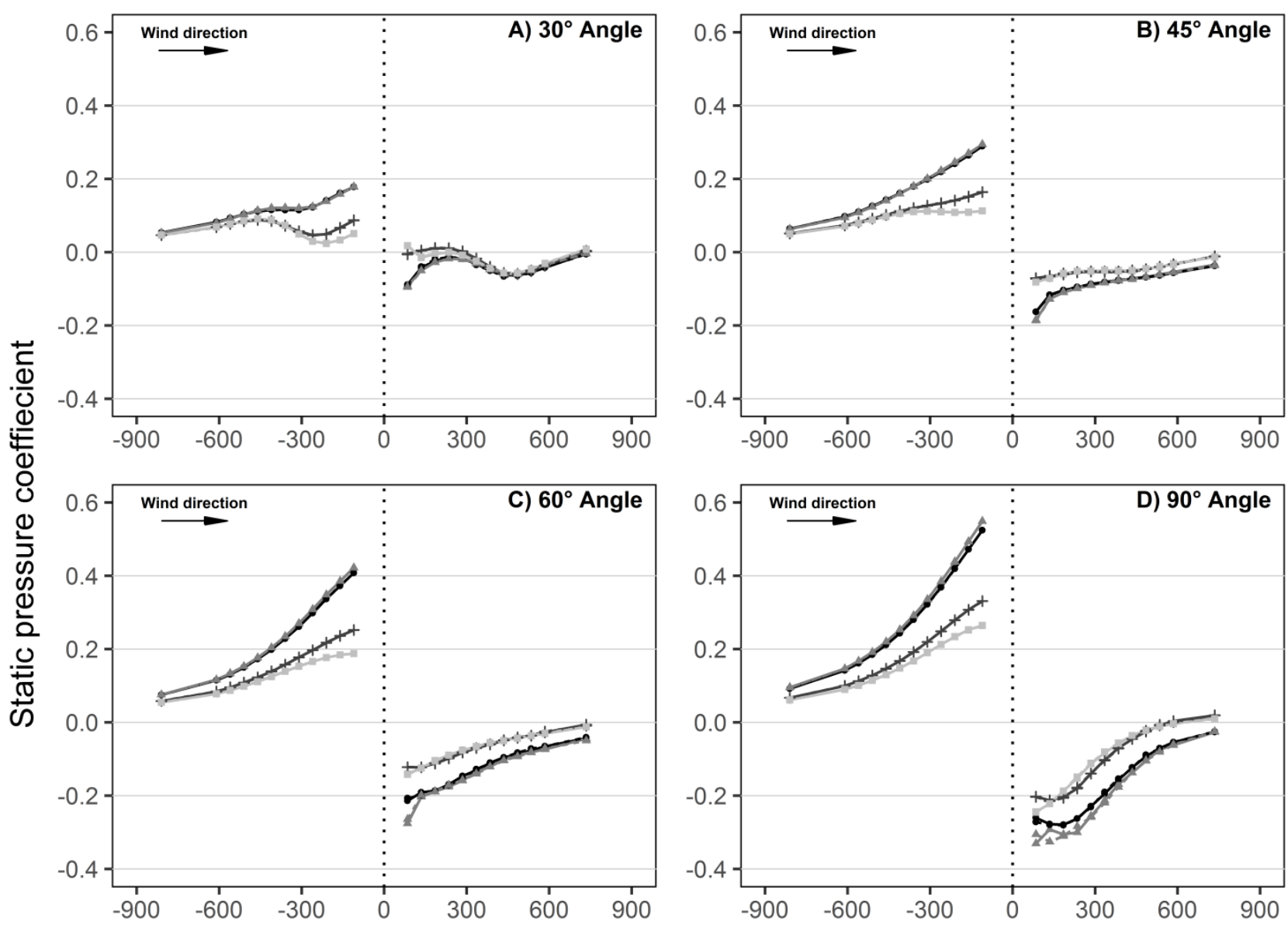

Position relative to grid $(\mathrm{mm})$

Grid $\rightarrow$ Cylindrical $\longrightarrow$ Drop $(4 \mathrm{~mm}) \longrightarrow \operatorname{Drop}(8 \mathrm{~mm}) \longrightarrow$ Rectangular

Line Pos.

BetweenBars_Line

Figure S2. Static pressure coefficient at different distances in front $(x<0)$ and behind $(x>0)$ the grid surface $(x=0$, marked by the vertical dotted line) for the approaching velocity of $\approx 17.3 \mathrm{~m}^{-1}$ and aligned with the central bar of the grid for the four grid angles. 

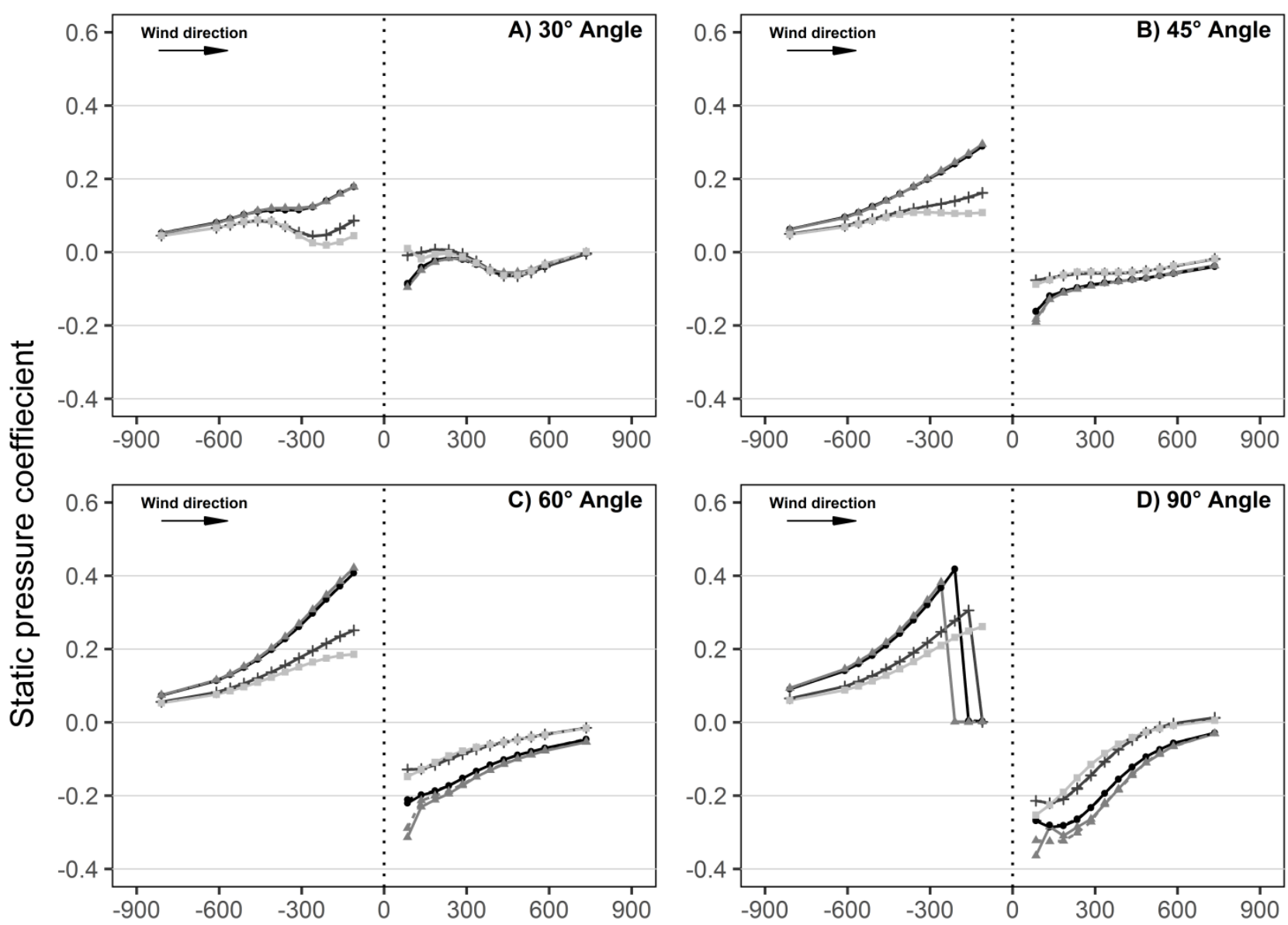

Position relative to grid $(\mathrm{mm})$

Figure S3. Static pressure coefficient at different distances in front $(x<0)$ and behind $(x>0)$ the grid surface $(x=0$, marked four grid angles. 


\section{${ }^{*}$ Author Contributions Section}

Tiago Veiga-Malta: Conceptualization, Methodology, Investigation, Writing - Original Draft, Visualization, Writing - Review \& Editing. Karsten Breddermann: Conceptualization, Methodology, Investigation, Validation, Writing - Original Draft, Writing - Review \& Editing. Jordan P. Feekings: Conceptualization, Resources, Writing - Review \& Editing, Funding acquisition. Ludvig A. Krag: Writing Review \& Editing, Supervision. Mathias Paschen: Resources, Writing - Review \& Editing, Supervision. 